\title{
Correction to: India's labour question is also a social question: inequalizing growth and increasing social inequality under neoliberal economic regimes
}

\section{K. P. Kannan ${ }^{1,2}$}

Published online: 25 September 2018

(c) Institute for Social and Economic Change 2018

Correction to: J. Soc. Econ. Dev. (2017) 19(2):263-282 https://doi.org/10.1007/s40847-017-0045-z

The article title in the original version contained a mistake. The correct wording of the article title is given above.

The original article can be found online at https://doi.org/10.1007/s40847-017-0045-z.

\section{K. P. Kannan}

kannankp123@gmail.com

1 Centre for Development Studies, Trivandrum, Kerala, India

2 Laurie Baker Centre for Habitat Studies, Trivandrum, Kerala, India 